\title{
Arthroscopic observation was useful to detect loosening of the femoral component of unicompartmental knee arthroplasty in a recurrent hemoarthrosis
}

\author{
Kotaro Yamakado ${ }^{1 *}$, Hitoshi Arakawa ${ }^{2}$ and Seigaku Hayashi ${ }^{1}$
}

\begin{abstract}
A case of recurrent hemarthrosis of the knee after a mobile-bearing unicompartmental knee arthroplasty (UKA; Oxford UKA) is described. A 58-year-old man met with a road traffic accident 10 months after UKA. He developed anteromedial pain and hemarthrosis of the knee joint 1 month after the accident, which required multiple aspirations. Physical examination showed no instability. Plain radiograph revealed no signs of loosening. All laboratory data, including bleeding and coagulation times, were within normal limits. Diagnostic arthroscopy demonstrated loosening of the femoral component. Any intraarticular pathology other than nonspecific synovitis was ruled out. The loose femoral component and polyethylene meniscal bearing were revised. Since then, hemarthrosis has not recurred.
\end{abstract}

\section{Background}

Recurrent hemarthrosis after knee arthroplasty is a rare complication. The occurrence is presumed to be less than $1 \%$ in total knee arthroplasty (TKA) [1-9], and it is merely reported after UKA $[10,11]$. The reported causes of hemarthrosis after TKA are impingement of the fat pad or hypertrophic vascular mass of the synovium, femoral flare eroding through an atherosclerotic superior lateral genicular artery, and pigmented villonodular synovitis [1-9]. The reported lesions in nonprosthetic knees are anterior cruciate ligament tears, major meniscus tears, osteochondral fractures, posterior cruciate ligament tears, and coagulation disorder [12-17].

We report a case of recurrent hemarthrosis after UKA caused by loosening of the femoral component.

\section{Case report}

A 58-year-old man met with a road traffic accident 10 months after a mobile-bearing unicompartmental knee arthroplasty (UKA, Oxford UKA; Biomet, Swindon,

\footnotetext{
* Correspondence: yamakadok@gmail.com

'Department of Orthopaedics, Fukui General Hospital, 58-16-1 Egami, Fukui, Fukui 9108561, Japan

Full list of author information is available at the end of the article
}

United Kingdom). His car was struck from the side at an intersection. He could walk on his legs; however, he complained a bruise on the anterior knee. The outcome of the arthroplasty was good with radiological evidence of well-fixed implants before the accident. However, he developed pain and hemarthrosis of the knee joint 1 month after the accident, which subsequently required multiple aspirations of blood (30-50 $\mathrm{ml})$ at an interval of 3-12 days. The range of motion was normal $\left(0 / 140^{\circ}\right)$, but the patient complained of anteromedial knee pain. Physical examination showed no instability. Plain radiograph revealed no signs of loosening such as radiolucent lines or osteolysis (Figure 1). A small bony gap anterior to the femoral component and a small posterior overhanging were noted in the lateral view of $x$-ray, however, there was no change compared with the immediate post operative radiographs. All laboratory data, including bleeding and coagulation times, C-reactive protein, ESR were within normal limits. Diagnostic arthroscopy demonstrated loosening of the femoral component and a stable tibial metal tray by palpation with an arthroscopic probe, showing a space between the femoral bone surface and the femoral component (Additional 


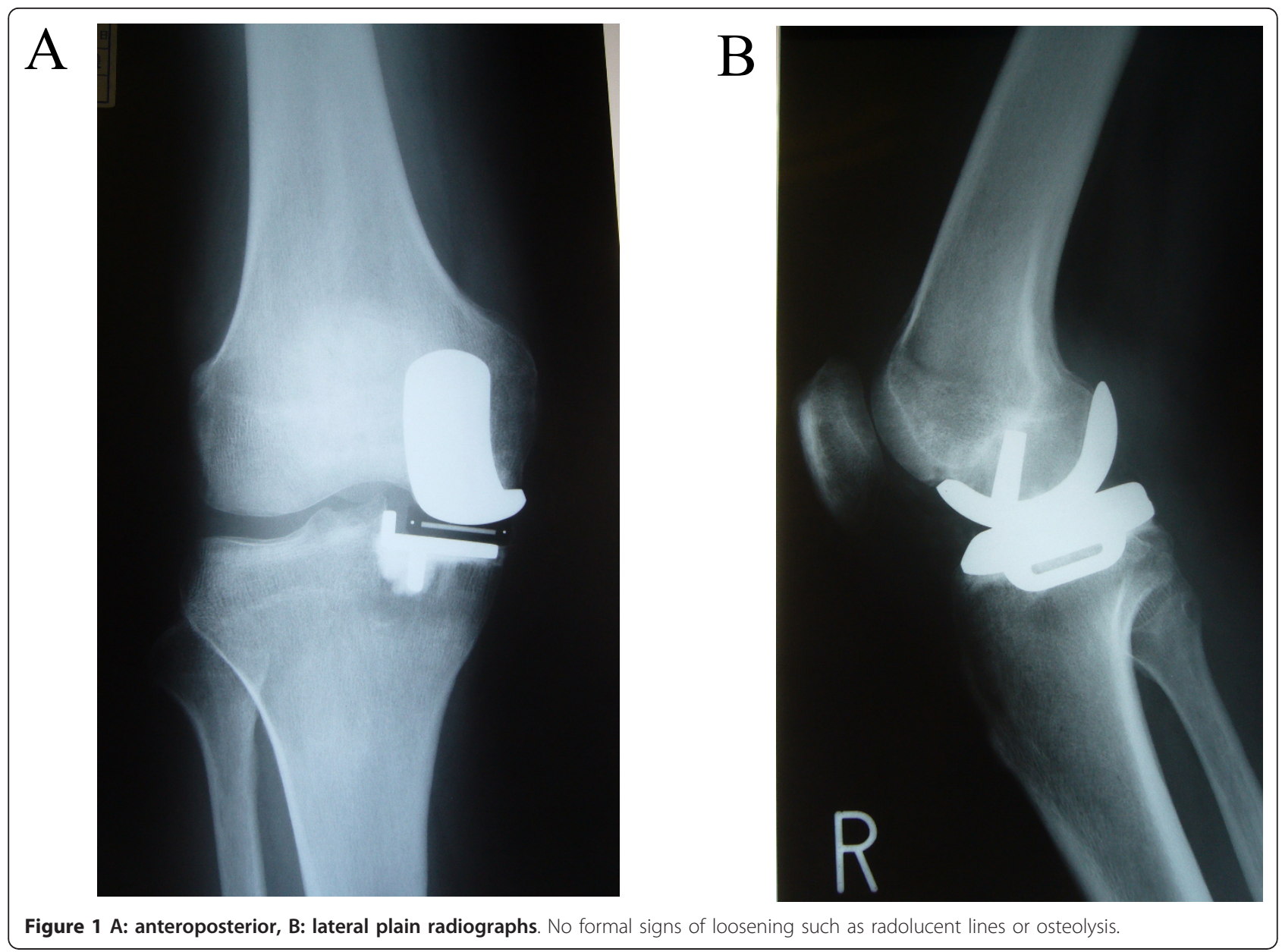

file 1: video, http://www.smarttjournal.com/imedia/ $1188539294566234 /$ supp1.mpeg). Any other intraarticular pathology including anterior cruciate ligament tears, meniscus tears, osteochondral fractures, posterior cruciate ligament tears, vascular blush other than nonspecific mild synovitis, was ruled out. Synovial tissue and jont fluid was taken as a bacterial culture and was of negative results. After completion of the arthroscopy, an anterior midline mini-arthrotomy incision measuring approximately $5 \mathrm{~cm}$ was made through the previous scar. The loose femoral component and polyethylene meniscal bearing were revised. At the boneprosthesis interface, the cement was primarily intact around the peg, with the loosening occurring at the bone-cement interface. No membranous tissue was observed on the backside of the femoral component and on the cutting surface of the femoral condyle. Since then, hemarthrosis has not recurred until final follow up at 3 years after the revision surgery and the patient was doing well with Knee Society knee score and function score at the latest follow-up evaluation were 95 and 90 points, respectively.

\section{Discussion}

To our knowledge, this is the first report of recurrent hemarthrosis caused by femoral component loosening after UKA. We suppose that a direct blow on the operated knee caused a micro-crack of the cement between the component and the femoral bone surface, which extended to loosening; at the emergency room, he complained a bruise on the anterior knee, indicating that the femoral component was caught between the dashboard and the femoral bone surface. It appeared that micromotion of the component caused a continuous bleeding from the bone bed, which gave rise to recurrent hemarthrosis in a semi-acute setting. In this case, no membranous tissue was observed on the backside of the femoral component and the patient had been doing well before the accident, indicating the acute/semi-acute nature of the loosening. Any other intra-articular pathology was ruled out by the arthroscopic exploration. Mild infection should also be ruled out at every revision surgeries, however, bacterial culture, blood analysis, and postoperative course suggested that infection was unlikely in our case. The circumstantial evidence points to the 
trauma as a cause of component loosening. Recurrent hemarthrosis after UKA, in itself, is a very rare complication $[10,11]$. There are only two cases were reported in English literatures. Maheshwari reported a case of spontaneous hemarthrosis caused by the saphenous branch of the descending genicular artery with a prominent vascular blush, which was successfully treated by coil embolization [10]. Raet reported a case of spontaneous hemarthrosis caused by traumatic rupture of the metal marker wire of an all-polyethylene inlay tibial implant, which caused destruction of the polyethylene surface and a disseminated synovitis [11]. The reported causes of hemarthrosis after TKA or in nonprosthetic knee are cruciate ligament tears, meniscus tears, osteochondral fractures, impingement of the fat pad or hypertrophic vascular mass of the synovium, and pigmented villonodular synovitis [1-9,12-17]. Arthroscopic examination had successfully ruled out these intra-articular pathologies in our case. Loosening of the femoral component after UKA (Oxford UKA) is the second most common cause of revision, and the incidence ranges from $0 \%$ to $2.1 \%$ [18-21], however, diagnosis of femoral component loosening is difficult [21]. Symptoms related to component loosening are nonspecific and are usually reported as pain. Hence, it is very important to determine this early in the clinical course. There might be very subtle changes on standard anteroposterior or lateral radiographs before osteolysis occurs. Thus, comparison between early post-operative radiographs and present radiographs may show migration of the component. However, it is difficult to distinguish the loosening of femoral component using radiographs because back surface is concave and bonecement interface cannot be seen in radiographs. Moreover, it must be required to delineate the difference between pathological and physiological, non progressive, such radiolucencies which have been shown to be common and not related to loosening. Recently, as an alternative, Monk et al. described a technique using lateral extension and flexion radiographs [21], which might to be a powerful tool to obviate the need for artrhroscopy. We think that the arthroscopy is invasive and should be reserved procedure, however, it would be very worthful if other examination methods failed to specify and/or rule out the component loosening.

\section{Conclusions}

In conclusion, our case showed that loosening of the femoral component might lead to recurrent hemarthrosis and suggested that arthroscopic exploration was thought to be one of useful methods to diagnose and, especially, to rule out other intra-articular pathology.

\section{Additional material}

Additional file 1: A space between the femoral bone surface and

the femoral component is shown.

\section{Abbreviations}

UKA: Unicompartmental knee arthroplasty; TKA: Total knee arthroplasty.

\section{Author details}

'Department of Orthopaedics, Fukui General Hospital, 58-16-1 Egami, Fukui, Fukui 9108561, Japan. ${ }^{2}$ Arakawa Orthopaedic Clinic, Fukui, Japan.

\section{Authors' contributions}

KY and HA participated in this study and KY drafted the manuscript. SH supervised this study. All authors read and approved the final manuscript.

\section{Competing interests}

The authors declare that they have no competing interests.

Received: 24 April 2011 Accepted: 21 February 2012

Published: 21 February 2012

\section{References}

1. Kindsfater K, Scott R: Recurrent hemarthrosis after total knee arthroplasty. J Arthroplasty 1995, 10(Suppl):S52-5, PMID: 8776056 [PubMed-indexed for MEDLINE]

2. Worland RL, Jessup DE: Recurrent hemarthrosis after total knee arthroplasty. J Arthroplasty 1996, 11:977-978.

3. Katsimihas M, Robinson D, Thornton M, Langkamer VG: Therapeutic embolization of the genicular arteries for recurrent hemarthrosis after total knee arthroplasty. J Arthroplasty 2001, 16:935-937.

4. Oishi CS, Elliott ML, Colwell CW Jr: Recurrent hemarthrosis following a total knee arthroplasty. J Arthroplasty 1995, 10(Suppl):S56-8, PMID: 8776057 [PubMed-indexed for MEDLINE].

5. Cunningham RB, Mariani EM: Spontaneous hemarthrosis 6 years after total knee arthroplasty. J Arthroplasty 2001, 16(1):133-135.

6. Braverman DL, Kern HB, Nagler W: Recurrent spontaneous hemarthrosis associated with reflex sympathetic dystrophy. Arch Phys Med Rehabil 1998, 79(3):339-342.

7. Ballard WT, Clark CR, Callaghan JJ: Recurrent spontaneous hemarthrosis nine years after a total knee arthroplasty. A presentation with pigmented villonodular synovitis. J Bone Joint Surg Am 1993, 74:764-767.

8. Fink B, Berger I, Siegmuller C, Fassbender HG, Meyer-Scholten C, Tillmann K, Ruther W: Recurring synovitis as a possible reason for aseptic loosening of knee endoprostheses in patients with rheumatoid arthritis. J Bone Joint Surg Br 2001, 83:604-608.

9. Maheshwari R, Kelley SP, Langkamer VG, Loveday E: Spontaneous recurrent haemarthrosis following unicompartmental knee arthroplasty and its successful treatment by coil embolisation. Knee 2004, 11(5):413-415.

10. De Raet J, Verhaven E, Kemnitz S: Late spontaneous haemarthrosis: an unusual complication following an unicompartmental knee arthroplasty. Knee Surg Sports Traumatol Arthrosc 2007, 15(6):763-765.

11. Barber F, Prudich J: Acute traumatic knee hemarthrosis. Arthroscopy 1993 9(2):174-176.

12. Butler JC, Andrews JR: The role of arthroscopic surgery in the evaluation of acute traumatic hemarthrosis of the knee. Clin Orthop Rel Res 1988, 228:150-152

13. Dehaven KE: Diagnosis of acute knee injuries with hemarthrosis. Am J Sports Med 1980, 8(1):9-14.

14. Gillquist J, Hagberg G, Oretorp N: Arthroscopy in acute injuries of the knee joint. Acta Orthop Scand 1977, 48:190-196.

15. Noyes FR, Bassett RW, Grood ES, Butler DL: Arthroscopy in acute traumatic hemarthrosis of the knee. J Bone Joint Surg 1980, 62-A(5):687-695.

16. Bomberg BC, McGinty JB: Acute hemarthrosis of the knee: indications for diagnostic arthroscopy. Arthroscopy 1990, 6(3):221-225.

17. Lewold S, Goodman S, Knutson K, Robertsson O, Lidgren L: Oxford meniscal bearing knee versus the Marmor knee in unicompartmental 
arthroplasty for arthrosis: a Swedish multicenter survival study. J Arthroplasty 1995, 10:722-731.

18. Murray DW, Goodfellow JW, O'Connor JJ: The Oxford medial unicompartmental arthroplasty: a ten-year survival study. J Bone Joint Surg [Br] 1998, 80-B:983-989.

19. Pandit H, Beard DJ, Jenkins C, et al: Combined anterior cruciate reconstruction and Oxford unicompartmental knee arthroplasty. J Bone Joint Surg [Br] 2006, 88-B:887-892.

20. Price AJ, Waite JC, Svard U: Long-term clinical results of the medial Oxford unicompartmental knee arthroplasty. Clin Orthop 2005, 435:171-180.

21. Monk AP, Keys GW, Murray DW: Loosening of the femoral component after unicompartmental knee replacement. J Bone Joint Surg Br 2009, 91(3):405-407.

doi:10.1186/1758-2555-4-8

Cite this article as: Yamakado et al: Arthroscopic observation was useful to detect loosening of the femoral component of unicompartmental knee arthroplasty in a recurrent hemoarthrosis. Sports Medicine

Arthroscopy, Rehabilitation, Therapy \& Technology 2012 4:8.

\section{Submit your next manuscript to BioMed Central} and take full advantage of:

- Convenient online submission

- Thorough peer review

- No space constraints or color figure charges

- Immediate publication on acceptance

- Inclusion in PubMed, CAS, Scopus and Google Scholar

- Research which is freely available for redistribution

Submit your manuscript at www.biomedcentral.com/submit 